The Geneva Papers on Risk and Insurance, 23 (No. 86, January 1998), 14-33

\title{
Insurance in the Light of Financial Theory and Innovation
}

\author{
by Ambroise Laurent*
}

Insurance has long been considered an autonomous economic activity devoted exclusively to risk management and using special techniques to do so. As protection needs increased faster than wealth produced, the future of this industry and growth of its scope seemed assured.

However, insurance can also be seen as a financial business line specialized in the collection, management and payment of precautionary savings according to predetermined rules (contractual losses, maturities, policyholder's options, etc.). From this angle, the insurer is a financial player like any other.

This system is undergoing fundamental changes. Although its functions have remained the same (allocation of funds in space and time, risk management, etc..), the way in which they are accomplished has radically changed under the impact of deregulation and innovation (e.g. emergence of derivatives markets, securitization, financial engineering, etc.). This has modified the role and activity and even the scope of financial institutions. Will insurance be able to avoid these major changes?

To improve our understanding of this sector and its current and future changes, I believe we need to approach it in the light of financial theory and ongoing efforts to innovate by upgrading the effectiveness and efficiency of the financial system. This will improve our grasp of the specific features of the insurance industry, the origin and nature of its changes and their limits and obstacles.

* M. A. Laurent, Director, AXA/UAP, Place des Saisons, 92083 Paris La Defense, France. The author wishes to thank Thierry Dubois, Rémy Jourde and Eric Sugier, as well as François de Varenne and Eric Briys, who moderated the "Insurance and Finance" seminar organized by Denis Kessler at the FFSA, for their advice. 


\section{Contributions of the financial approach}

Financial theory and its successive enrichments can be used to update and improve traditional analysis of the insurance business.

This approach also casts light on the origin of shortcomings in the recent history of certain insurance companies and lays the groundwork for new management instruments and improved insurance operations.

\subsection{Shortcomings of traditional approaches}

Historically, insurance has been primarily defined as a technique used to spread losses sustained by certain insured persons over an entire body of policyholders. Mutualization and the laws of statistics (such as the law of large numbers) have often been called essential and integral factors of life and non-life insurance alike.

Rapid examination of the areas in which insurers carry on their business shows that this technical definition is not always appropriate and relevant. Indeed, insurers can cover a specific risk without mutualizing it with risks of the same kind. Moreover, they do not always fall back on statistics laws, either because all policyholders are entitled to the insurer's benefits (e.g. insurance with savings elements) or because of lack of reliable information about frequency or average cost (new risks). Lastly, when a risk is particularly high, insurers use transfer techniques (coinsurance and reinsurance) in order to spread it over several companies and limit their own exposure.

More recently, insurance has been defined by reference to production of economic goods and services. According to this approach, the insured requests a protection service for his own consumption from a specialized producer, the insurer.

Unfortunately, this attractive approach does not factor in the dual nature of the service rendered, which consists in an intangible protection service as well as a financial service (only for policyholders sustaining a loss or for all policyholders). Like the technical approach, this analysis remains influenced by the characteristics of non-life insurance and seems less appropriate for life insurance.

While these traditional analyses make it possible to explain the origin of the liabilities of insurance companies to some extent, they do not factor in asset management services by insurers. Thus, it has been written that "investment by insurance companies merely complements their core business, which is to sell protection." (Rosa, 1970)

Considering asset management incidental to technical operations reflects a strong bias in favor of non-life insurance. This error, visible in daily management at many insurers, was the driving force behind the adventurous behavior which prompted inappropriate investment of assets held to cover linked liabilities by certain companies, exposing them to losses which endangered their very existence or slashed their profitability.

This philosophy is also reflected in the assertion that an insurance company must base its management strategy on constant efforts to achieve an underwriting balance. From this point of view, financial income is an additional remuneration which is either kept by the insurer or shared with the policyholders (under a profit sharing clause). 
In practice, and especially in commercial operations, it is obvious that the underwriting promise and the financial promise of insurance products are closely blended. There is no competitive automobile insurance rate which does not factor in the possibility of a financial discount ${ }^{1}$. Similarly, two life insurance products with the same technical characteristics are distinguished by their respective financial performances.

To sum up, traditional approaches do not satisfactorily factor in reality and promote segregated management of the company's asset and liabilities. This management approach has potentially far-reaching consequences which run counter to benefits served on policyholders. It is unfortunate that insurance instruction is mainly limited to this traditional underwriting view, as witness many university textbooks (e.g. Mehr, Vaughan, Lambert).

\subsection{Interest of a financial and functional interpretation of insurance}

Life as well as non-life insurers collect savings in return for a promise to return them to the body of policyholders. Such savings are paid back either to policyholders who incur losses (risk insurance) or to all policyholders in proportion to savings collected in case of agreements without underwriting risk (e.g. investment insurance certificates). The savings paid back to policyholders are complemented by all or part of the financial income generated between collection and reimbursement.

The pure premium is calculated by matching on a discounted basis savings collected with the sum of benefits earmarked for the collective policyholders (including financial income). The commercial premium is found by incrementing the pure premium with intermediation costs and the margin needed to finance the risk premium expected by the shareholder (whose capital is tied up to cover the volatility of the pure premium), less that share of financial income generated by investment of collected savings kept by the insurer ${ }^{2}$.

In a way, it can be said that the insurer's technique lies in his ability to calculate pure and commercial premiums. However, his skill does not stop there.

The insurer needs financial know-how in order to redistribute collected savings to other economic players looking for capital. Such reallocation must be optimized in order to generate a maximum return (so as to lower the pure or commercial premium and/or to maximize financial income allocated to policyholders and shareholders) while keeping such investments sufficiently safe and liquid.

As a general rule, it can be said that an insurance company raises funds from shareholders and policyholders for investment in an asset portfolio (their leverage depends on the actual regulatory minimum capitalization coverage rate). The difference between

1 In risk insurance in general, the underwriting deficit measures the implicit interest rate necessary for the mathematical reserves. In other words, the cost of savings collected from policyholders is precisely measured by the underwriting deficit.

${ }^{2}$ In passing, it may be noted that the regulations require insurers to apply a precautionary discount rate which is disconnected from market rates and significantly lower.

In return, the regulations for instance limit the sums taken by (life for example) insurers from financial income generated by investment of premium income. 
the return on assets and the cost of liabilities is designed to cover intermediation charges (marketing + management). Return on equity is the endogenous variable of the equation bearing the volatility of its other terms (Kopcke, 1995).

From this angle, the insurer is a financial intermediary who "takes risks" with his liabilities as well as his assets.

Loubergé (1981) was one of the first to describe insurance as a financial activity in an uncertain economy. More precisely, he defined an insurance contract as a conditional claim acquired by the policyholder from an issuer-insurer. This definition, which applies to risk insurance ${ }^{3}$, could be completed by adding that the insurer's skill lies in his ability to determine the issuing price of his claims (according to their precise contractual terms) and to invest collected savings in such a way as to be able to cover his debt at all times.

The development of option evaluation models since 1973 (Black \& Scholes) and financial derivatives markets in the eighties have acquainted the financial community with concepts which are very useful for specifying Loubergé's intuition and so offering a better description of the insurer's activity.

When an insurer engages in risk insurance he sells his clients put options for different elements of their assets (human or material) at strike prices which depend on the scope of coverage (nil if cover is available only for total loss, from zero to the asset value if partial losses are covered). In return for a premium, policyholders acquire the right to transfer their losses to the insurer ${ }^{4}$. Deductibles and wear coefficients (which lower the strike price), indemnification ceilings (which are like caps on the sold option), etc. help build up a precise outline of the option profile acquired by the policyholder.

This option-based interpretation also applies to pure savings life insurance. Briys and de Varenne (1994) have shown that a single premium contract tied to a guaranteed minimum rate and a legal profit sharing clause can be construed as a combination of a high-risk obligation (i.e. a zero coupon without risk less the default option held by the shareholders) and an option to buy part of the financial income. This basic combination is complicated by other options such as the policyholder's right to advances or redemption. Such "hidden" options have widely drawn the attention of actuaries and supervisory authorities, owing to their liquidity risks.

In other words, an insurance contract can financially be considered a structured product. The financial concepts developed in the last twenty years can be used to analyze insurance contracts in order to gain a better understanding of the nature of the financial product sold to the policyholder and the associated risks. For example, the above authors have shown that the liquidity risk linked to the early redemption option is low compared with the rate risk generated by the profit-sharing option. The duration of mathematical reserves is much more affected by this latter option than by the redemption clause. The real duration of liabilities is therefore quite frequently shorter than the duration of the corresponding assets. Owing to this spread, widened by the leverage (ratio of

\footnotetext{
${ }^{3}$ In pure savings insurance, the claim is certain.

${ }^{4}$ Like other lenders, policyholders sell the company's shareholders an option to default when assets make it impossible to satisfy liabilities.
} 
mathematical reserves to equity), invested capital is excessively exposed to the rate risk (see 32 below). Most insurers tie their investment strategy to the maturities of their liabilities, even though they should have factored in the much shorter duration of those liabilities.

\subsection{Growing awareness of three aspects}

This financial approach to insurance contracts and the insurer's activity have fostered growing awareness in the fields of rates, regulations and asset-liability management.

- As regards rates, it has been shown that insurers have not made clients pay the theoretical price of the offered option mix, notably in the area of life insurance. While it is difficult to establish a precise rate for some of these, insurers are implicitly aware of the risks incurred, since they penalize the use of some of these options.

This solution is unsatisfactory : in addition to a technical and actuarial approach, an insurer must make every effort to measure the nature and sensitivity of the options which he sells to his clientele, and raise his rates to factor in a fair additional remuneration for the shareholder when risks are retained or to include the cost of coverage in the premium when risks are transferred to a third party (if there is an instrument to do so). An insurance company may also restrict its product line in order to exclude options which are difficult to control and/or price.

Here it should be noted that it is difficult to value many such options since valuation not only factors in their objective characteristics, sometimes making them similar to exotic options, but also the behavior of policyholders. As Boulier (1996) indicates, "The main difference between traditional options and these options lies in the behavior of their holders. An option held by a professional investor is exercised when the result is profitable. This is not the case with retail investors or debtors (or policyholders). This means that analysis needs to focus on the behavior of clients, as necessary by segment."

- The financial approach has also made it possible to establish new regulatory criteria for calculating the minimum solvency standards required to carry on an insurance business. Since December 1992, US standards are defined according to the RBC model (riskbased capital model), which factors in four main risk categories: investment, underwriting, rate volatility and general management.

This new regulation takes account of the risks generated by technical and financial portfolios and by more or less coordinated management of such asset and liability portfolios. While not a perfect reference in its own right, it reflects better understanding of the insurance business and casts new light on the ongoing European talks. Indeed, by 1 July 1997, a report must be presented on the need to revise the regulatory solvency criteria applicable to insurers in the Union. Currently, solvency is determined exclusively as a percentage of premium income volume or claims experience (in non-life insurance) and mathematical reserves (in life insurance). This is obviously inadequate.

- Lastly, insurers have become aware of the need to flesh out the accounting and actuarial approach of their assets and liabilities. In many countries, assets are booked at historic value, enabling insurers to limit the impact of market fluctuations on their balance sheet. Actuarial analysis of liabilities makes it difficult to factor in the characteristics of the 
options sold implicitly or explicitly by insurers to their clients 5 . Without knowing it on reading his balance sheet, an insurer may be in a speculative position due to lack of adequate matching between assets and liabilities ${ }^{6}$. Current accounting rules make consequences of limited changes in financial rates and the behavior of policyholders invisible on the balance sheet and income statement. The insurer does not realize the economic consequences of these environmental changes on his actual wealth.

This financial view underlies a major concrete change observed in insurance companies in recent years, i.e. growing concern with asset-liability management, gradually replacing complete segregation of investment and underwriting management. In the past, managers of traditional insurance companies felt no need for coordination since high equity and especially unrealized capital gains enabled them to absorb the volatility accompanying asset allocation which focused on high-risk investments (equity, real estate) rather than low-risk investments. Traditional insurers, especially in the life insurance branch, were consequently all the more inclined to engage in large-scale financial transformation as the cost of their resources matched and sometimes even exceeded the income which could reasonably be expected from their bond investments, which left no margin to cover intermediation costs and return on equity. The "solution" was to look for higher interest by investing in excessively long maturities or high-risk assets in violation of asset-liability management rules.

The emergence of new types of insurers (direct insurers in the non-life branch, banking subsidiaries in the life insurance branch) initially fostered growth of a financial management approach aimed primarily at satisfying commitments to policyholders. Thus, the competitive rates of direct insurers on the market of private clients were not only due to lower intermediation costs but also to regularly higher financial income. The same applied to banking subsidiaries, which invested mostly in fixed-income products, thus strengthening their commercial success at a time of positive and historically high real interest rates. These new players demonstrated that, for an insurer, assets are liability production factors.

Low equity and lack of unrealized capital gains to underpin capital also explain why these new competitors decided not to take the risk of failing to match liabilities and investments. Thus, most banking subsidiaries immediately developed suitable assetliability management tools enabling them to construct congruent asset portfolios for each

5 In the example on investment insurance certificates at a guaranteed rate, the current commitment calculation does not factor in either the profit-sharing option or secondary options.

${ }^{6}$ As a general rule, it can be said that an insurer's equity is exposed to rising as well as easing rates (short straddle position). The market value of an insurer's liabilities reaches a floor when rates rise, since liabilities are pegged to inflation (in non-life insurance) and redemption and advance clauses are exercised (in life insurance). Conversely, when rates go down, the market value of reserves rises to the degree that the insurer has factored in a minimum interest rate in his non-life rates and in the savings interest guarantees of his life insurance. The market value of matching assets does not change symmetrically and in the case of certain investments even moves in the opposite direction (e.g. low sensitivity of a convertible bond portfolio when rates go down). When rates decrease, market value of assets rises more slowly than that of liabilities. When rates rise, assets lose value faster than liabilities. To sum up, the market value of equity, i.e. the value of the difference between assets and liabilities), decreases when rates rise as well as when rates go down. 
category of contracts with different technical characteristics. These portfolios are managed to align with changes in the volume and structure of the corresponding liabilities.

Traditional insurance companies are beginning to grasp the changes required in their operating methods. This generally prompts them to segregate assets, and to increase the weight and shorten the duration of bond investments.

The function of insurance is not limited to supplying protection against hazards. It also engages in asset allocation, just like banks and markets. An insurer performs several interlinked financial functions. Insurers cannot ignore the fact that coordinated performance of these tasks alone justifies their existence.

Thus, an insurer is not just a risk management specialist. Nor can he pretend to be the only specialist in this area.

\section{A new vision of risk management methods}

Theoretical analysis of the risk management solutions available to economic players show the role of actuarial insurance in a larger framework. This will enable us to explain the origin and weight of the different forms of what seems to be "disintermediation" in the insurance sector.

Indeed in the past, insurers have all too often felt that their business was limited only by the inability to insure certain risks. The contributions of risk theory and risk management make it easier to understand why and how their scope of business may be limited by the emergence of new forms of behavior vis-a-vis risk itself and by new forms of risk management. In other words, insurance is not the only solution against risks.

\section{1. Theoretical approach}

Every economic player in a net asset position and/or with the capacity to generate a net asset position is exposed to risk. Risk can be defined as any event capable of negatively affecting net assets and/or the capacity to increase net assets. Many risks contribute to this uncertainty, which is inherent in every human activity. Some are entirely under the control of the economic player himself, while most are only partly or not at all under his control.

Faced with a given hazard, an economic player always has the choice of putting his present or future capital at risk or reducing or eliminating his exposure to such risk. In theory, every rational player will try to keep only those risks which he can control, i.e. those connected with his talents and his ability to produce value-added, and will protect himself against other risks which he knows he cannot control by transferring them fully or partly to another agent.

It is important to stress that, at a macro-economic level, the entire risk is finally borne by the available capital. In other words, death, accidents, unemployment and natural disasters always generate loss of current or future wealth for the entire economic system. On first analysis, risk management merely modifies allocation between different economic players, thereby enabling these players to produce more value-added than they would have had if their exposure to risks had not been modified. However, risk management 
actually reduces the total risk volume thanks to the significant impact of the accompanying prevention measures.

Detailed risk management methods are therefore not neutral. This is demonstrated by on-the-job accidents, whose intensity varies according to whether they are financed by compulsory insurance managed by a single agency (the French situation) or whether they are covered by optional insurance available from several players (the American situation). In both cases, insurers resort to actuarial insurance but prevention works better when several insurers are in competition. The best way to reduce the cost of risk is to minimize its frequency and intensity. This is the function and impact of prevention, which in the final analysis reduces the overall risk volume.

We will turn to Mason (1995) to borrow his three main risk management methods: hedging, diversification and insurance.

- Hedging enables an economic player to protect himself against a given risk by eliminating it. This is done by using an immediate or deferred transaction consisting in exchanging, immediately or subsequently, the asset underlying the undesirable risk for another asset. On the organized financial assets or commodities markets, the various transaction methods (spot, forward, future, swap) are a first way of protecting oneself against the uncertainties connected with holding a given asset. This is a radical solution since it relieves the transferor from the risk of loss but also deprives him from the possibility of gain on the underlying asset just sold. Such an agent is moreover exposed to the uncertainty connected with the new underlying asset obtained on completion of the transaction (cash or asset obtained in return).

- Diversification consists in reducing overall exposure to risk by holding not just one underlying asset but a combination of different assets (with the same value as the initially held single asset). This technique is based on the observation that non-identical risks do not add up arithmetically (the correlation between the underlying assets is less than 1) and may even offset each other (correlation between 0 and -1 ). This insight underlies portfolio diversification strategies which, by combining several dozens of financial assets of the same kind (e.g. stocks) but of different origin, eliminate almost all of the volatility linked to the specific risk of each asset and only keep the market risk (measured by the volatility of the overall category of assets).

- Insurance can be defined as a contract to transfer all or part of an undesirable risk to a third party in exchange for payment of a premium. Insurance can either be optional or actuarial. The first insurance method is used for specific risks tied to standard underlying assets and is currently used primarily for financial assets (e.g. interest rates, exchange rates, stock indexes, options, etc.). Actuarial insurance deals with risks linked to more diversified, non-standard or even complex underlying assets (persons or property). Actuarial insurance is not always available when there are insufficient data, e.g. on the extent and frequency of the risk.

Any financial system which takes charge of the given risks of certain economic players and transfers them to other players is a form of risk management. It is institutional in the case of actuarial insurance but it may also take the form of an organized market or over the counter trade in case of hedging, diversification or optional insurance. 
Thus, risk management does not necessarily resort to actuarial insurance.

\subsection{Practical consequences}

- Insured risks have to some extent been reduced in recent years by the fact that certain economic players retain a larger share of risk. Any economic player with a certain size (companies, local authorities let alone states) is exposed to many frequent risks of low intensity connected with a portfolio of underlying assets whose behavior shows little correlation. As a result, the aggregate risk of the agent concerned is much lower than the sum of hazards connected with these assets.

Thus, it is in the economic player's interest to preserve his given risk exposure if the cost of transfer to an insurer exceeds the expectation of loss.

In the recent history of corporate risk management, the rise of self-insurance in all its forms (retention, deductible, profit sharing clause, reinsurance by a captive company, etc.) was primarily driven by growing awareness that de-facto diversification of a company's assets enables it to support a maximum number of "small risks" to which it is exposed on optimum economic conditions, without recourse to third parties.

- Moreover, since the beginning of the decade, different forms of optional insurance have emerged to replace traditional insurance methods.

For instance, in 1992 the Chicago Board of Trade launched an option market, based upon US natural disaster options index. This index, recently modified and improved, reflects the intensity of damage caused on American territory by meteorological phenomena (purchase of a call spread on this index amounts to using an excess loss coverage caped with an aggregate). Direct insurers and reinsurers buy such options in order to reduce exposure. Their counterparties are reinsurers and investors, e.g. those whose activity is correlated inversely to the claims experience concerned (e.g. construction companies). Although trade in this index is growing slowly, it should be stressed that OTC trade in this index is estimated at twenty times the volume of standard transactions.

More recently, another form of optional insurance has emerged in the form of bonds whose reimbursement terms are negatively affected when a predetermined loss occurs. In other words, an economic agent exposed to a given risk covers this risk by raising additional capital which he will only reimburse in full (incremented by interest to cover the risk premium and to reward the sellers of the default option) if the expected risk does not occur. Examples of this form of insurance are the earthquake loan of the State of California and Winterthur's frost bond issue ${ }^{7}$.

More generally, optional insurance can be expected to gain ground. This activity can be practiced by many more financial intermediaries (institutional investors, speculative funds, arbitragers, etc.) than insurance companies alone. These intermediaries have

\footnotetext{
${ }^{7}$ In the first case, the State directly called on the financial markets to raise the funds used to cover the losses borne by it in case of an earthquake. Investors have replaced insurers and reinsurers to share this major risk together. In the second case, an insurer himself considered it to his advantage to transfer part of the risks in his portfolio to investors rather than to reinsurers.
} 
access to much larger capital resources than traditional insurers ${ }^{8}$ and are attracted by the fact that such newly created financial assets normally have little correlation with already existing financial assets.

In 1996, Bryan and Farrell noted the following about the capital market: "Activities connected with derivatives and structuring techniques are creating an efficient market on which the price of risks is fixed homogeneously throughout the world. By making prices more uniform and isolating risks, derivatives and structuring techniques have made the market clearer and more efficient (...); global intermediation practices are evolving in favor of the market and to the detriment of banks". While insurance has not yet reached this stage, notably as regards individual risks, this trend can be expected to gather pace as regards major risks, which cannot be eliminated globally but must be distributed and shared.

Moreover, the theoretical cost of the protection offered by optional insurance can be determined beforehand, which facilitates comparison of services and obliges operators to improve the transparency of their prices.

These factors will help lower margins and prices in favor of protection buyers.

"Financial markets exist to transfer risks between the participants", as Chiappori indicates (1996). If innovative formulas are found to convert risks transferred by means of actuarial insurance instruments (or their underlying assets) into negotiable securities, the markets may gradually replace the risk management intermediaries known as insurers (Cossu and Mansion, 1996).

"Alternative risk management methods" are emerging at the crossroads of these two trends (retention of risks and optional insurance). Implemented by investment banks, insurers and reinsurers, such methods are designed to enable large operators to manage a growing portion of their risks without recourse to traditional actuarial insurance, using the array of new technical and financial instruments described above.

\section{Limits of a purely financial approach}

Having reviewed the contributions of financial theory and innovation to actuarial insurance and risk management, we must now examine the arguments most often used to defend the specific function of insurance companies, re-examine the environment in which asset-liability management has emerged and determine the limits of the new risk management methods.

\section{1. The specific function of actuarial insurance}

- The first argument is that insurers are skilled in the art of aggregating mutualized risks (and dividing major risks between operators). Risk transfers eliminate a policyholder's earlier uncertainty. By pooling highly diverse risks with little correlation between each

${ }^{8}$ As pointed out by Briys (1997) with respect to Swiss $\mathrm{Re}$, the potential losses linked to the aggregate risk of global natural disasters exceed the combined equity of insurers and reinsurers. This said, the $\$ 10$ billion in losses run up in respect of these covers from 1989 to 1995 equal the impact of a change of less than 10 basis points on the American financial markets. 
other within a single structure, an insurer can replace the initial uncertainty with a known loss (the pure premium), limited by the impact of diversification and division.

An intermediate structure may be necessary to pool liabilities, but the structure which markets contracts is not necessarily the counterparty.

For example, banks, which book all kinds of loans under assets on the balance sheet, may, for certain types of facilities, be replaced by institutions whose business is limited to marketing loans and whose claims are held by mutual funds financed directly on the financial markets. Thus, American banks have gradually been shouldered out of the private home loan market.

In other words, the ability to manage a mutualized structure does not seem adequate in itself to offer the insurer protection. As Chiappori writes, "mutualization consists in grouping a large number of independent risks within a common structure": but there is no reason why this structure should be the same as the institution which collects such independent risks.

- The diversity of risks transferred to the insurer reflects the diversity of underlying assets. The assets underlying a given type of risk (mortality, automobile damage, disability, etc.), are of the same type (human lives, automobiles, ability to work). However, such assets cannot be standardized and are notably not represented by financial securities. It is therefore argued that the insurer is capable of taking charge of risks which cannot be standardized.

But the foregoing example of the natural disaster options index shows that it is possible to create a direct derivatives market (used to trade options) without having a primary financial market on which to trade securities representing underlying assets. It is therefore possible to imagine option markets organized to hedge against or speculate on changes in human longevity, changes in the automobile claims experience or changes in disability rates and the average time of disability.

This obviously raises many practical problems, such as the need to define the phenomena concerned and ways to measure them objectively. Theoretically, however, securitization of property and personal risks should be able to flourish. This would open the door to alternative methods of managing such risks (such as optional insurance) ${ }^{9}$.

- Lastly, the insurer applies special know-how to control the adverse consequences of risk transfers.

\footnotetext{
${ }^{9}$ Discussing banks, Bryan and Farrell (1996) stress that the "most important advantage of securitization is probably that it will always be more profitable to securitize a loan or borrowing than to enter it on the balance sheet of a bank". Like credit institutions, insurers with liabilities on their balance sheet must ipso facto tie up (and compensate) equity and finance their intermediation costs. Securitization makes it possible to separate collection and management of liabilities, transferred directly via the financial market to investors. Transfer via the balance sheet of a bank or insurer adds cost because of the need to compensate the equity tied up by these institutions to guarantee their solvency. (Theoretically, lack of an ultimate solvency guarantee on the financial markets should raise the risk premium claimed by investors. In practice, the rise of securitization tends to show that this risk premium remains below the premium demanded by financial institutions).
} 
Insurance primarily attracts those whose assets (human, tangible or intangible) are most exposed. This well-known phenomenon of antiselection ${ }^{10}$ is controlled by active preliminary inspection (medical selection in life and health insurance) and portfolio surveillance (elimination of "bad" risks in property, casualty or liability insurance).

Moreover, the very fact of transferring a risk to another economic agent does away with the policyholder's incentive to adopt prudent behavior designed to reduce the probability and size of losses. This prior moral hazard is offset by specific incentives such as deductibles, no-claims bonuses, profit sharing clauses and discounts. The moral hazard which occurs afterwards, which is not the same as fraudulent behavior, is controlled by inspections designed to make sure that policyholders do not pad their real losses.

This know-how, all too restrictively referred to as "underwriting quality", is what enables professionals to control their underwriting income, i.e. the cost of savings collected from policyholders (excluding their financial remuneration). In other words, this know-how makes it possible to guarantee that a pure premium which is correctly calculated beforehand does not turn out to fall short after the fact ${ }^{11}$. The laws of supply and demand lead to pricing cycles which may explain a certain rate volatility around the equilibrium level of the pure premium. But over an average period, an insurer who masters calculation of this equilibrium level must control antiselection and the moral hazard in order to make sure that his prior estimate fully matches his results.

Is it possible to dissociate the function of risk taking itself from the function of verifying the consequences of transfers between economic players? The theoretical and especially the practical answer to this question is definitely a sine qua non for the future of new methods to manage risks currently still transferred to insurers.

To sum up, actuarial insurance may in the future be up against competition in the very area of what it considers its major strengths.

The insurer's best protection lies rather in his ability to adapt his services to the needs of his clientele. Given the modularity of insurance contracts, the scope of their covers ("all risk except" type clauses) and flexibility of their provisions (cancellation and early redemption clauses or, conversely, extension clauses, etc.), the development and use of other risk management formulas are unlikely. They would only be attractive if they were to perform the same functions at lower cost.

Financially, an insurance contract can be considered a complex package with many options (in the case of savings contracts grafted onto a risk-free financial asset). While it is

${ }^{10}$ Antiselection and moral hazard are not limited to insurance. Banks are confronted with the same phenomenon, e.g. in their lending business: bad customers pay too little compared with good customers while borrowers are not given an incentive to limit their risks.

11 A pure premium which afterwards turns out to be too high (e.g. generating an underwriting profit) would not have been correctly calculated beforehand. In fact, it would not correspond to the real cost of the risk and, in theory at least, the laws of competition would reduce prices to their equilibrium level. However, as the real market is far from this pure and perfect, an operator can base his strategy on exploitation of risks or market segments on which he is able to charge rates in excess of the correctly calculated pure premium. 
theoretically always possible to break such a package down into basic options, insurers seem to offer real value-added given their ability to develop, produce and market such structures by presenting them as simply and accessibly as possible! There is no denying the power of any institution capable of identifying and satisfying the increasingly sophisticated expectations of the clientele ${ }^{12}$.

In the final analysis, there is an obvious paradox: what theoretically weakens the traditional insurer is what protects him in practice. However, doesn't the insurer weaken his profitability by protecting his business this way? The insurer who adds complexity to his contracts without charging his clients a fair price places two bets: first, that he is commercially capable of attracting clients by catering to their many expectations, and secondly, that his policyholders will not use all these contractual options on a large scale.

\section{2. Conditions for growth of asset-liability management}

The complexity of insurance contracts is also a drawback for the insurer since it limits the opportunities to pursue a financial strategy according to the cardinal principles of assetliability management.

The purpose of asset-liability management is to protect the economic value of an insurance company by means of an investment strategy which is not so much based on abstract considerations as on analysis of current liabilities and on mechanisms to make sure that new liabilities are based on the conditions of the financial market (unless matched, such liabilities cannot be managed without exposing equity).

In particular, as the sensitivity of assets and liabilities to interest rate fluctuations differs significantly, the value of equity is affected increasingly by this exogenous volatility as leverage (liabilities to equity) rises ${ }^{13}$.

The purpose of asset-liability management is to control this hazard, directly linked to the financial intermediation function served by the insurer and measured by high

12 The development of assistance in-kind services to complement and/or to replace traditional financial indemnities adds to the complexity of insurance contracts and helps protects it from threatened substitution by alternative risk transfer formulas.

${ }^{13}$ Simply put, assuming that the assets (A) are equal to the sum of liabilities (L) and equity (E) and taking respective asset and liability durations DA and DL, we can simulate the sensitivity of equity to interest rates as follows :

$$
S_{E}=\frac{-1}{E} \frac{d E}{d y}=\left(\frac{d L}{d y}-\frac{d A}{d y}\right) \frac{1}{E}=\left(\frac{A D_{A}}{1+y}-\frac{L D_{L}}{1+y}\right) \frac{1}{E} \text { since } S_{x}=\frac{-1 d x}{x d y}=\frac{D x}{1+y}
$$

This gives

$$
D_{E}=D_{A}+\left[D_{A}-D_{L}\right] L / E
$$

The duration of equity is equal to the sum of the duration of assets and the duration spread between assets and liabilities multiplied by the leverage.

Equity is not exposed if $S_{E}=0=D_{E}$, which means that the ratio between the duration of assets and liabilities must be inversely proportional to their amount $\left(D_{A} / D_{L}=L / A\right)$. In other words, the duration of assets should exceed the duration of liabilities to the degree that equity increases compared with liabilities $\left(D_{A}=D_{L}(1-E / A)\right)$. 
sensitivity of the market capitalization of insurance companies to changes in the value of assets and notably interest rates.

This has become a major concern for insurers, who endeavor to manage the duration spread between their investments and liabilities in order to minimize exposure of equity (a complete approach would make it not only necessary to manage this spread in order to protect the company against small rate changes, but also convexities in order to avoid exposure in case of large changes). This strategy runs into major difficulties with measuring the sensitivity of mathematical reserves and their corresponding assets.

Asset evolution parameters can be determined by means of historic performance (yield and volatility) on the markets where such assets are traded and the projections offered by such markets. However, this is only possible with assets which are permanently listed. Less liquid investments (real estate, unlisted stocks, etc.) can only be included in asset-liability management models by making outright assumptions about the yield and/or volatility of such assets.

Liability evolution parameters are much harder to determine reliably. In life insurance, how should one determine beforehand the sensitivity of redemption rates to changes in interest rates and yield on assets? In non-life insurance, which assumptions should be applied to sectoral inflation, which directly affects the value of liabilities? In strict financial terms, it is difficult to value at all times the price and volatility of the options held by policyholders. As Valin notes (1996), "the duration of assets and liabilities is not of the same kind (...). Liability evolution parameters do not follow the principles of the financial markets." This raises considerable application problems, which are not enough stressed in theoretical works (see Price Axa 1994 manual).

This problem can be viewed from another slant: the duration of assets and liabilities is often calculated according to the Macaulay formula, which assumes that the cash flow of a given asset or liability does not change in case of a change in interest rates. For insurance companies, cash flow connected with assets and especially liabilities is generally not stable. Owing to the existence of "hidden" options, it varies according to interest rates.

As Babbel points out (1994), the fact that sensitivity of cash flow to interest rates is not taken into account produces major calculation errors ${ }^{14}$. A seeming decrease in the

${ }^{14}$ The sensitivity of a financial instrument to the interest rate $y$ is equal to the relative change of price $P$ of this instrument, induced by an infinitesemal change in this rate $\left(S=\frac{-1}{P} \frac{d P}{d y}\right)$.

As $P$ is equal to the sum of discounted future cash flows ( $\mathrm{CFt}$ ), sensitivity can be expressed according to Macaulay's duration $\left(D=\frac{1}{P} \sum \frac{C F t}{(1+y) t} \mathrm{t}\right)$.

Since it is assumed that CFt is fixed, $\frac{d P}{d y}=-\sum \frac{C F t}{(1+y)^{t+1}} \mathrm{t}$.

Thus, $S=\frac{D}{1+y}$.

However, the cash flows (CFt) vary according to $\mathrm{y}$. Therefore, $\frac{d P}{d y}=-\sum\left(\frac{C F t}{(1+y)^{t+1}} t+\frac{d C F t / d y}{(1+y)^{t}}\right)$ and Macaulay's duration no longer correctly reflects the sensitivity of the instrument to the interest rate. 
duration spread between assets and liabilities can actually conceal a growing sensitivity spread.

When there is no or unreliable knowledge of cash flow sensitivity (notably as regards liabilities), it is impossible to work out an asset-liability management strategy. As Babbel notes, "It is useless to use simplistic approaches to treat complex problems". This may especially be dangerous.

In practice, asset-liability management remains relatively "rusticated" in insurance companies. It is impossible to conclude that it protects equity fully or even largely against the risks inherent in the financial transformation assumed de facto by the insurer.

Babbel and Stricker (1987-1989) argue that asset-liability management does not necessarily need such an immunity objective. Indeed, this objective could sideline the insurer on the market. While asset-liability management focuses on risk control, other objectives, such as profit maximization, should not be forgotten. According to these authors, assets and liabilities need not be fully matched, depending on the choice between yield and risk (and interest rate volatility projections). This viewpoint should be rejected. The shareholder does not provide the insurer with equity to have the latter endeavor to post a gain by exposing it to exogenous risks linked to the trend of the financial markets, which it does not control, but to let it fructify by using its own expertise. In other words, the shareholder only wants to bear endogenous risks connected with the insurer's own business (business risks) and to be remunerated accordingly. The strategy described by Babbel and Stricker amounts to betting one's future on exogenous profitability when the object is endogenous value-added to compensate equity which must be protected against every uncontrolled hazard.

Conversely, recourse to deterministic asset-liability management models in practice prompts certain insurers to adopt an unfavorable attitude toward investments and toward contracts with the least certain cash flow profiles. However, to remain true to his vocation, the insurer cannot refuse liabilities aligned with the complex requirements of his clients or refuse to invest in assets such as stocks and real estate, capable of guaranteeing in the long term a performance in excess of fixed-income products (and protection against inflation). Failing this, his very existence may be jeopardized ${ }^{15}$.

\subsection{Limits of new risk management methods}

\section{- Self-insurance}

Which economic players can forego transferring their risks to a third party by means of an insurance mechanism and can bear the impact on their equity? In the interest of which economic players is this?

Recent advances in financial theory stress that it is in the shareholder's interest to invest in high-risk assets when the additional risk is compensated by a higher yield and diversification enables the shareholder to trim total portfolio volatility to the average

${ }^{15}$ An insurer must nevertheless give priority to assets whose functions are the same but whose risk profile can be controlled. For instance, inflation-linked bonds, where they exist, are a better match than assets which can be revalued for liabilities which require protection against price hikes. 
volatility of the market. The shareholder does not expect a company to manage the endogenous risks which he takes intentionally when investing in such company. From the investor's point of view, acquisition of protection of the insurance type against such risks by a company financed by many shareholders may be considered useless reduction of profits ${ }^{16}$.

This does not apply to protection of personal assets by households (whose property is little diversified except for the wealthiest) nor to small and medium-size enterprises, generally representing most of the property of one or more individuals. Granted, the limited liability clause protects the remaining property of such individuals; but in the case of sole proprietorships or SMEs, the investment in the business generally corresponds to most of the shareholders' assets. Protection of this investment, even if it means reducing its profitability, is therefore quite valid in this case.

This explains a fact which is well-known among insurers: the most durable and profitable insurance demand on a mature market comes from households, individual entrepreneurs and SMEs.

It is also in the interest of non-profit organizations and local authorities to use insurance. In fact, these economic players are financed by voluntary or compulsory contributions from households and businesses, which do not behave like investors: such funds are not collected for compensation but must above all be protected against the risk of loss. In fact, it is necessary to minimize the need for additional finance designed to offset loss of assets due to transferable risks. Of course, given that such risks offset each other, transfer should not be by specific hazard, which would moreover tax the daily resources (and the insurance capacity) of such institutions, but should concern the aggregate risk to which the property of such economic players is exposed ${ }^{17}$

The State is a special case in two respects:

- Given that it is the only player with the sovereign power to divide losses over the largest number by means of taxation and given that it institutionally guarantees the durability of the economic and social fabric, it is the insurer in last instance. Accordingly, the State cannot ignore the way in which economic players manage their risks. Decisions defining risks for which players themselves are liable and risks covered in first or last instance by the State, whether explicitly or implicitly, are essentially political. Accordingly, it would be paradoxical for the State to transfer part of the risks assumed back to private capital.

- To protect the property of the State itself, the State is its own insurer, which means that it does not transfer its risks to private capital. However, there is space for certain transfers of specific risks to private players if, and only if, this makes it possible to

${ }^{16}$ By contrast, the investor will expect the company to protect itself in an optimum way against the totally exogenous risks to which it is exposed and which it cannot control.

${ }^{17}$ If the net cost of insurance (spread between commercial premium and pure premium) is higher than the borrowing cost, it is theoretically in the interest of the economic agent to retain his risks and to take out a loan in order to cover his losses, reimbursed by a share of his future income whose present value is less than the net insurance cost he would have to pay for transferring his risks. Such a strategy implies the ability to analyze different risk management methods as well as the ability to borrow enough to cover potential losses. 
pursue a prevention strategy and so to reduce the transferred risk. An insurer who agrees to cover this risk may do so on condition that protection measures are taken which would not have been taken without its intervention. If such measures actually lower the risk (by reducing its frequency and/or its average cost), its transfer increases macro-economic wealth, which will partly benefit the State, partly the private economic players involved in such transactions.

This example shows that the risk management method is not only determined by financial criteria: it is important to include behavioral factors in the analysis.

In this respect, it is of interest that aversion to risk seems to increase as net worth increases. In macro-economic terms, insurance consumption grows faster than GDP, even when we limit ourselves to risk insurance only. At micro-economic level, an improved standard of living should logically prompt individuals to take increasing charge of small risks (e.g. complementary health insurance). However, in practice households seem to become more "riscophobic" as they get wealthier, which, against all rational expectations, guarantees growth of insurable matter.

These behavioral factors are essential and give a better understanding of the risk management policies actually implemented by major companies.

\section{- Major companies}

As we have seen, major companies should in theory not transfer their risks to third parties. In fact, such risks are either of low intensity and can therefore be absorbed without difficulty by the company's own capital or are of high intensity but rare and therefore an essential risk deliberately incurred by the shareholder, for which he demands payment of a risk premium to pad the expected yield ${ }^{18}$.

Granted, recourse to an insurer gives companies access to a complete array of additional services, such as risk evaluation and prevention, and claims management. But the growth of risk management in companies shows that it may be in their economic interest to separate these functions from the risk transfer itself. This also applies to claims management, even though insurers can offer considerable expertise in this area, linked to the many losses managed. In fact, this service can be managed entirely independently provided an incentive system is implemented in order to link the remuneration of the specialized service provider to minimum final cost of loss for the company. Recourse to internal management or subcontracting of such services makes it unnecessary for companies to transfer their risks to insurers.

However, in practice companies may still find insurance to their advantage if the premium is less than the sum of the pure premium and the internal cost of evaluation, prevention and management services connected with such transfer. This explains why risk managers have become buyers, enabling companies which manage their risks optimally to exploit rates at the bottom of the cycle (when premiums are below their economic equilibrium). Thus, management of captives shows that retention rates vary in inverse proportion to reinsurance prices.

\footnotetext{
${ }^{18}$ It is obvious that an economic activity which incurs one or more risks of high intensity and high frequency will only be able to obtain public or speculative financing.
} 
This analysis also makes it easier to understand the paradoxical risk management logic followed by one of the oil majors. As a general rule, large companies retain their small risks and protect themselves against large risks. By contrast, this major oil company transfers its small risks on the grounds that their premiums are less than the sum of real risk costs and associated services (it is important to note that this is not structural but linked to cyclical surplus-capacity for this type of insurance). For mid-size risks, this oil company pursues an opportunistic strategy, transferring risks when rates are low and retaining risks when premiums rise above the equilibrium price. Lastly, this company no longer internally insures very large risks, on the grounds that the necessary protection costs would be higher than the risk premium expected by investors, who in return have accepted this major hazard. Here it may not be amiss to point that this highly satisfactory reason for the theoretician is complemented by a fiscal reason: a major loss would give this oil company a tax credit which would come in perfectly to reduce the final loss suffered by the company and, in the final analysis, its shareholders. This said, this company has pushed application of the theoretical reasoning very far.

Mayers and Smith (1992) stress that there are other reasons why companies have recourse to insurance. In fact, it reduces the conflict of interest between the shareholders and other parties interest in the company's future.

For instance, lenders have other interests than shareholders. Since they do not share in the company's profits, it is in their interest to demand transfer of the largest risks to third parties. This explains why loan contracts (e.g. to finance major investments) include clauses requiring the borrower to take out insurance in order to be able to reimburse the lender at all times.

Similarly, the personnel of a company whose future is uncertain will theoretically demand higher compensation. This payroll spread may exceed the cost of protection needed to guarantee the future of the business.

Lastly and above all, the situation and future of a company's managers are primarily linked to the survival of the company and only secondarily to its results. It is not always easy for a manager to make the shareholders accept a highly volatile performance, even if this is the price paid for higher profitability. Partial transfer of risk which should theoretically have been retained makes it possible to achieve a balance between the interests of management (the decision makers) and the shareholders.

To sum up, the development of new risk management methods will not inevitably lead to a lower volume of risk transfers. By contrast, from the view of the insurance industry, the economic conditions of such transfers can only worsen under the threefold impact of competition, better informed purchase behavior and increasing segregation of the function of risk taking itself and the services automatically associated with it in the past.

\section{Conclusion}

The foregoing analysis shows that there is no more simple and intangible answer to the question: "What is an insurer?"

The technical definition of this business line is clearly inadequate. The insurer is a financial intermediary who collects and redistributes savings designed to protect his 
policyholders against contractually defined risks. This function as an intermediary includes such specialties as technical development and management of liabilities, asset management, commercial and administrative management and connected services.

There can only be insurance if these three functions are performed, not separately from each other, but in close and balanced relation. This approach to the insurance business makes it necessary to:

- define and supervise one's liabilities (through pricing, underwriting and cancellation policy) and one's investments in order to guarantee a balance between collected savings and redistributed savings;

- search continually for the best matching of assets and liabilities, in the light of the yield and risk expectations expressed by clients and shareholders;

- control and improve one's competitiveness, tied to intermediation costs (marketing + management).

This said, it is not necessary that these three functions be performed by the same institution.

The creation of asset management subsidiaries, agreements with outside marketing networks and subcontracts for all or part of administrative management clearly show that integration of these business lines is not necessarily the best solution. Recourse to specialists capable of generating higher value-added than a given stage in the financial intermediation known as insurance demonstrates that the institutional description of this business line is outmoded and must be replaced by a functional description. This also makes it easier to understand the recent change in insurance companies, after revolutionizing banks, which is not so much a form of "disintermediation" as the dawn of new forms of intermediation.

In this paper, we have outlined the factors underlying the emergence of risk management methods which offer an alternative to insurance, as well as the first experiments in optional insurance instead of traditional actuarial insurance. True, their growth remains limited and does not undermine the expansion of traditional insurance demand, which is fueled by economic growth. Moreover, their emergence is slowed by many brakes. The biggest obstacle lies in the ability of actuarial insurance to continue adjusting itself to the protection needs of the economic players, notably those who are its most loyal customers, e.g. households, small companies and non-profit organizations.

For economic agents who are ready to leave the beaten path, the emergence of these new risk management techniques opens up growth and profitability prospects as less capital is needed to operate in this area than in actuarial insurance.

To sum up, the strategic question becomes "In what way can one be an insurer?" and, much more broadly, "In which area of risk management can one generate supplementary value-added?"

The complete composite insurer who manages all aspects of the business internally may take advantage of economies of scale. But he must be ready to adjust the way in which he carries on his business, since the operators who manage to build up a durable 
competitive edge in one of the foregoing functions will be the key players in the future insurance environment. Tomorrow's insurer will probably be a conductor who knows how to select and supervise the best operators in each business line to manage risks with optimum efficacy and profitability in order to pay the highest return on the capital collected to cover such risks, whether collected by a company or a reinsurer, on an organized market or in any other way.

One thing is certain: this sector will experience new upheavals resulting from major financial developments in the past, present and future.

\section{REFERENCES}

BABBEL, David; "Asset-liability matching in the insurance industry in the financial dynamics of the insurance industry", edited by E. Altman and I. Vanderhoof, Irwin, 1994.

BABBEL, David; STRICKER, Robert; "Asset-liability management for insurers. Insurance prospects", Goldman Sachs, 1987-1989.

Befec Price, "Axa - assurances: gestion et analyse financière"(chapter V, Gestion actif-passif), L'Argus Editions, 1994.

BOULIER, Jean-François; “Que valent les options cachées ?”, Revue d'Economie Financière, No 37, 1996.

BRIYS, Eric; DE VARENNE, François; DILLIES, Bernard; "Tarification et réglementation", Risques No 19, 1994.

BRIYS, Eric; DE VARENNE, François; “Assurance et intermédiation financière" dans encyclopédie des marchés financiers, Economica, 1997.

BRIYS, Eric; "From Genoa to Kobe: natural hazards, insurance risks and the pricing of insurancelinked bonds", Lehman Brothers, 1997.

BRYAN, Lowell; FARRELL, Diana; “Market unbound”, Wiley, 1996.

CHIAPPORI, Pierre-Andre; "Risque et assurance”, Flammarion, 1996.

COSSU, Pietro; MANSION, Yves; “Assurance et finance : vers un pont à double voie ?" Risques, No. $28,1996$.

KOPCKE, Richard; "Financial innovation and standards for the capital of insurance companies", New-England Economic Review, 1995.

LAMBERT, Denis-Clair; “Economie des assurances”, Armand Colin.

LOUBERGE, Henri; "Economie et finance de l'assurance et de la réassurance”, Dalloz, 1981.

MASON, Scott; The allocation of risk in "the global financial system", Harvard Business School, 1995.

MAYERS, David; SMITH, Clifford; The corporate insurance decision in "the revolution in corporate finance", edited by J. Stern and D. Chew, Blackwell, 1992.

MEHR, Robert; "Fundamentals of insurance", Irwin.

ROSA, Jean-Jacques; “Les placements des sociétés d'assurance”, thesis, University of Paris, 1970.

VALIN, Gérard; A propos de "Gestion et analyse financière", Chroniques, Risques No. 24, 1995.

VAUGHAN, Emmett; "Fundamentals of risk and insurance", Wiley. 